\title{
BUILDING A FOUNDATION FOR SUCCESS THROUGH STUDENT SERVICES FOR ONLINE LEARNERS
}

\author{
Dr. Ruth Newberry \\ Duquesne University \\ Catherine DeLuca \\ Duquesne University
}

\begin{abstract}
Retaining students in distance education programs requires institutions to field a strategically aligned, cross-unit team able to provide streamlined and effective services to online learners throughout the student's academic life (from applicant to alumni). If any team member drops the ball during interaction with the online student, the student becomes frustrated or distracted, and student retention is jeopardized. In today's highly competitive marketplace, students have a "universe of opportunities" for obtaining an education and advancing their careers. Attracting and retaining students is crucial to traditional institutions like Duquesne University in order to remain competitive in the online education marketplace. The university's recent commitment to formalizing graduate courses online has brought strategic planning, oversight, resources, and support to students. The Online Campus director initiated an examination of the services necessary for online students to be successful learners. As Duquesne found out, retaining online students goes beyond offering resident-equivalent services to online learners; it requires a holistic and networked approach that leverages existing technologies and an institutional commitment to its online learners, or what the authors have designed as the COMFORT model.
\end{abstract}

\section{KEYWORDS}

Online student, student services, support services, student-centric, academic services, holistic, teambased, online support models

\section{INTRODUCTION}

In Allen and Seaman's (2013) report on distance education in the United States, they estimated that 32\% of all students enrolled in post-secondary education were taking at least one online course. While the growth in online enrollment has slowed from previous years, it has continued to grow at a higher rate than the general student rate in higher education [1]. According to Online College Students 2013:

Comprehensive Data on Demands and Trends (2013), students who completed online courses or programs "considered it a good investment of their time and money" [2, p. 4]. In response to the overall growth of students in online programs, many traditional institutions are exploring online options as a new venture, and those institutions that have been offering online education are looking to expand their offerings to remain attractive to prospective students. The factors that continue to draw students, particularly graduate students, to online education are "scheduling flexibility" and "the freedom to manage other responsibilities" [2, p. 5]. In today's competitive and economically charged marketplace, colleges and universities cannot afford to be reactive to the needs of online students; rather, they need to 
proactively develop a strategic vision and plan to ensure online students have the best experience possible [3].

An institution's reputation, along with price, is critical in the decision process for prospective online students. Our proposed approach to online student services seeks to address the quality of interactions between the institution and its students. In Reworking the Student Departure Puzzle (2000), the authors suggested that an institution's engagement with its students is a significant factor in shaping online learners' experiences and outcomes [4]. Boston, Ice, and Gibson (2011) proposed that faculty, administrative staff and offices, and other students affect the kind of engagement students have with the institution, and the quality of these engagements is important to online students and their success [5]. Consequently, those institutions, such as for-profit institutions, that focus on the needs of online students continue to benefit from increased market share in online education [1,3]. With institutions cutting budgets and reducing staff and faculty during tight economic conditions, and the high cost of an education compounded by downward enrollment trends, institutions of all kinds must compete for a smaller pool of students [6].

Located in the urban setting of Pittsburgh, Pennsylvania, Duquesne University is a private liberal arts and doctoral research institution that entered the online education market in 1997. Like other traditional institutions, Duquesne has faced similar concerns with enrollment trends, budget tightening, and reduction in employees from retirement options. With 10,045 full-time equivalent students $(5,917$ undergraduates, 4,128 graduates), Duquesne offers its students educational opportunities within 10 schools of study. Founded in 1878 by Catholic missionaries from the Spiritan Order, Duquesne University is a mission-centered and mission-driven institution seeking to continue its strong heritage of social justice, commitment and service to the poor, ecumenicalism, and academic excellence through the experiences of its students, faculty, staff, and alumni. While a recent survey of undergraduate alumni captured the positive interactions students had with Duquesne [7], the responses of current online students reflected a more disjointed connection to the institution. The approach the authors describe in this article attempts to address this sense of disjointedness online students feel with Duquesne University as the institution becomes more strategic in how it competes in online education.

According to LaPadula (2003) and Crawley (2012), a positive student experience depends primarily on the quality of the interactions students have with an institution $[8,9]$. On-campus students interact with various departments, faculty, services, and peers across campus during their time at the university with the option to communicate in person with key institutional players as the students navigate through the system toward graduation. Online students, who must also interact with many of these same departments, faculty, and services, do not have the opportunity for in-person encounters. Instead, these students must rely on the contact methods the institution provides them, which all too often remain tied to campus operating hours and in-person procedures and any available web services. In her study on retention in higher education online programs, Heyman (2010) found that student satisfaction with the institution's support services was among the top contributing factors to retention. Students who feel supported by their institution are more likely to remain enrolled and eventually graduate, resulting in a positive or perceived positive experience with the institution [10]. Through improvements to the quality of university services, online students can be retained and, more importantly, form a lasting relationship with the institution. As online students achieve their goal of graduation and become alumni, the institution's alumni pool grows. When these alumni perceive a positive relationship with the institution, the institution's reputation and brand recognition is furthered through the positive support and outreach these alumni conduct in their communities. This brand recognition is, as Aslanian and Clinefelter found, one of the top three factors for students selecting an online education, along with accreditation and prospective students' acquaintance with other attendees [2, p. 5]. With a universe of options for online degrees available to prospective students, institutional brand recognition and reputation become critical considerations.

An effective student support services model for online students must not only work to retain students as Heyman (2010) notes, but it must also be strategic in nature, collaborative in effort, and originate from an analysis of what the institution is doing well and where gaps exist in its services to online students [10]. 
Smith (2005) suggests three key objectives to building effective and efficient online student support services: "identify the needs of its online and face-to-face learners; make services available when the learner wants them, rather than when the school is comfortable providing them; and provide online services that are as good or better than face-to-face equivalents" [11, p. 29]. Duquesne University is developing an effective student services plan grounded in Smith's (2005) key objectives for effective student online support services and the findings of LaPadula (2003) and Heyman (2010) regarding the relationships institutions construct with students through interactions $[11,8,10]$.

Our approach to this challenge is what we are calling the COMFORT model, a holistic strategy of providing services from which both the institution and online students benefit. The COMFORT model includes the following strategies outline in figure 1:

Figure 1. COMFORT Model

\begin{tabular}{|c|l|}
\hline $\mathrm{C}=$ & a well-developed communication plan for students, faculty, and support staff \\
\hline $\mathrm{O}=$ & orientations (plural) for students and faculty \\
\hline $\mathrm{M}=$ & the creation and maintenance of student-centered policies for success \\
\hline $\mathrm{F}=$ & $\begin{array}{l}\text { comprehensive feedback to improve existing support and academic services and to create new } \\
\text { ones }\end{array}$ \\
\hline $\mathrm{O}=$ & various outreach initiatives to students \\
\hline $\mathrm{R}=$ & easily accessible, learner-focused academic and support resources \\
\hline $\mathrm{T}=$ & $\begin{array}{l}\text { a team-based approach and commitment to online students' success during their academic } \\
\text { lifespan }\end{array}$ \\
\hline
\end{tabular}

The COMFORT model is a compilation of best practices and evidence based research that we as practitioners believe will improve the experience of Duquesne University's online students. Neither the authors nor the institution suggest compromising academic standards to fit the needs of online students. Instead, we propose that an effective student services model is a partnership between the institution and the online learner in the student's journey from applicant to alumnus that is grounded in a clear understanding of each other's expectations and responsibilities in this journey.

\section{BACKGROUND}

Duquesne University is not new to online education. Of the 10,045 students at Duquesne University, 724 are completing their degrees in online programs. These students, primarily graduate and working adult students, are enrolled in online programs offered through the following schools: Nursing, Leadership, Music, and Education. Duquesne's School of Nursing was one of the nation's first to offer an online doctorate in Nursing in 1997. Today, the School of Nursing includes online master's programs, a postmaster's certificate, a doctorate of philosophy in Nursing, a doctorate of nursing practice, and starting in fall 2014, a RN to BSN bridge program. The School of Leadership and Professional Advancement began its online master's program in Leadership in 2000, having already offered courses in its award-winning, accelerated bachelor of professional sciences available in online and face-to-face formats. The Mary Pappert School of Music and the School of Education moved selected programs and courses online starting in the late 1990s and the early 2000s.

A significant challenge for both online students and the Online Campus, which formed in November 2012, is the decentralization of services and support for online education at Duquesne University. Paperbased and in-person processes slowly transition to online-friendly processes, and early-adopter faculty individually venture into online education, causing Duquesne University's online student services to be scattered and uneven. While an entrepreneurial approach to online education moved Duquesne University early into the online education space, decisions as to which courses and programs should move online 
were not necessarily tied to enrollment trends and market needs. Today, the earlier entrepreneurial spirit must be tempered somewhat. As online education grows in popularity and viability for adult students, particularly as the disruptive presence of massive open online courses raises awareness of online education in the public consciousness, skepticism about the quality of instruction and learning dissipates. Alongside concerns about student debt and the value of higher education, mid-sized, brick and mortar liberal arts and research institutions like Duquesne University must determine the role and degree to which online education will have a presence in their strategic plans, their educational philosophy, and their identity. If they choose, as Duquesne has, to compete within the online education marketplace, then they must find ways to strategically allocate resources to build a sustainable infrastructure to support and retain students and faculty and to protect, enhance, and grow their brand within the constraints of market competition, institutional economic realities, and institutional identity and branding.

Even as Duquesne's decentralized structure enabled individual faculty and schools to develop schoolspecific online courses and programs, these paths have not been sustainable within ever-tightening budgets. And as our initial assessment of Duquesne's online learners revealed, they are experiencing student services unfriendly to online students and inconsistently applied across the institution. For instance, technical assistance remains tied to campus class schedule hours and the eastern time zone, while other forms of assistance are available only during university business hours by phone or e-mail. In 2013, the process to change a student's grade still required signatures on paper forms. However, as the institution addresses the requests of on-campus students for 24/7 access to class registration, course descriptions, drop/add procedures, course evaluations, and extended assistance for library research, more services are gradually becoming online-friendly for all Duquesne students.

With the November 2012 formation of the Online Campus, Duquesne University is signaling to the campus community that the university is strategically formalizing its efforts in online education by providing leadership, guidance, structure, processes, and advocacy for the institution's online students. Additionally, the recent restructuring of the Enrollment Management Group further aligns resources toward applying market trends to student recruitment and emphasizes student retention at the undergraduate and graduate levels. This restructuring has sparked many conversations across campus regarding the role of online education at Duquesne. Two themes are predominant in these campus conversations: faculty concern regarding professional development and assistance for teaching online and the preparedness of the campus to provide effective support services to online students. As the university tackles these broad challenges simultaneously, this article focuses specifically on improving student services for online learners. The assumptions underwriting this initiative to improve student services are

- the importance of Duquesne's mission and Spiritan tradition of "serving God by serving students" to enhance the experience of all Duquesne students [12];

- the student-centric approach Duquesne takes toward the educational experience of its students and faculty, acknowledging this approach as a critical differentiator and value-add element for online education at Duquesne;

- the institution's desire to grow graduate enrollments across the 10 disciplines through online opportunities;

- the necessity of bringing consistency to communications and processes across the schools for graduate services since Duquesne lacks a graduate school to centralize these efforts;

- the lessons learned from the Schools of Nursing, Leadership, Music, and Education's delivery of online programs and the small, dedicated workgroup they provided; and

- the importance of applying Duquesne's student-centric approach to course design and engaging faculty in student retention efforts.

In other words, to highlight the value added by an online Duquesne educational experience as expressed by faculty and students with both online and campus experiences, student support services needed to promote in the online realm the same sense of "connectedness" to faculty and services (or the representatives of the institution) as on-campus students said they experienced. Guiding our approach to 
Building a Foundation for Success through Student Services for Online Learners

this challenge of providing quality interactions between Duquesne and its online learners through necessary, easy to use, and timely support services that can be holistically and programmatically applied across all 10 disciplines in a cost-efficient manner, we adopted Smith's (2005) key objectives, which suggested this approach can lead to a wholly satisfactory online experience for online learners [11].

\section{EVALUATION}

To improve student services for online learners, we approached the problem from a practitioner perspective, which led us to examine current processes and services delivered to current online students. The evaluation, initiated by the Online Campus director, involved identifying the student support structure within the schools offering online programs and the university at large: their policies, procedures, and services for online students. Additionally, the authors undertook a review of best practices and strategies for supporting online students; school committees designed and deployed surveys to current online students and faculty teaching online. The Online Campus director gathered key stakeholders from across campus to investigate specific areas of concern and to identify and recommend areas for improvements.

The analysis of the support services structure for the schools offering online programs made obvious the strengths, weaknesses, and inconsistencies across the schools offering online education. For instance, the schools might have some but not all of the components Pipitone and Poirer (2011) describe as part of the student "life-cycle" or "the continuum of service from the first point of contact throughout the student's College experience" [13, p. 1]. While schools relied heavily on institutional functional areas, such as financial aid, health services, and career services, to help with servicing online students, the schools rarely had internal staff members for the high-touch points of the student's academic life, such as recruiters, admission counselors, advisors for enrolled student, and alumni officers to engage alumni. Lacking a graduate school to help with centralizing these services, our online student support model not only needed to design services around the academic life of the Duquesne online student, but also had to account for this lack of consistent structure within the schools offering online programs.

\section{A. Policies and Procedures Review}

Duquesne University currently offers 14 online degrees through four schools. From the review of policies, student handbooks, and procedures for online learners, the only thing that was consistent across the online programs was inconsistency. Although we had been providing online education for almost 20 years, school websites and course sites were difficult to navigate, and many common student tasks were not yet online student friendly. For example, academic integrity was presented differently among the four schools, with most relying on the instructor's course syllabus to state the school's policy and procedures. To begin correcting these issues, the School of Nursing is piloting an academic integrity module that requires online students to view a video explaining what academic integrity means to them as students and nursing professionals, particularly the expectations and responsibilities they have as learners, and to submit their acknowledgement in each course that they will comply with the policy before they can gain access to the content of the course. Additionally, the university's Academic Integrity Committee is nearing its work on standardizing school procedures with university policy.

\section{B. Task Forces}

During the spring 2013 semester, the Online Campus director initiated three ad hoc committees to assess the current state of online education and services at Duquesne University: the Online Orientation Committee, the Online Student Services Committee, and the Academic-Student Affairs Committee. The goals for these three committees aligned with the aims of the Online Campus School Committees that the director began in January 2013. These school committees were established in partnership with each school's dean and were intended to prompt explorations regarding the role of online education in the school and to identify faculty attitudes, program possibilities, faculty and student support needs, and to define required policies and desired procedures that would benefit online students and faculty teaching 
online. The three committees further broadened the conversations among key stakeholders regarding an appropriate and sustainable university infrastructure for online education, while keeping each committee of manageable size and thus schedule meetings. The Online Campus director was the constant throughout, providing information and possibilities for collaborating with other schools.

\section{Online Orientation Committee}

The Online Orientation Committee was charged with examining the current welcome information sent to students and orientation practices in order to develop a university-wide online orientation to bring consistency and accuracy to the information students received. The committee is currently designing a streamlined, technology-enhanced orientation process for new campus and online graduate students. Participants in this part of the study included graduate student representatives and representatives from International Programs, Graduate Admissions, and graduate advisors.

\section{Online Student Services Committee}

The Online Student Services Committee was tasked with identifying and reviewing the existing online student services for adequacy and ease of use in addition to assessing options for holistic improvements aligned with the university's motto of "education for the mind, heart, and spirit." Participants in this part of the study were graduate advisors in online programs and representatives from Financial Aid, Retention and Advising, Graduate Admissions, International Programs, and Veterans' Education.

\section{Academic-Student Affairs Committee}

For this committee, the Online Campus director worked with those units providing upcoming online education initiatives so they could (1) plan resources and staffing to service online students and (2) examine how their current processes might need adjustment to service online students if the units had not already done so. This committee was comprised of representatives from Academic Affairs, such as the University Writing Center, Gumberg Library, Retention Office, and Learning Skills Center, as well as units from Student Affairs, such as Career Services, Student Services (special needs), and Programs and Activities (Student Affairs). Additionally, a representative from Central IT's Help Desk also attended.

\section{Survey}

Outside of surveys from Alumni Affairs to recent university graduates and semester course evaluations, no attempts had been made to gather information specifically from online students regarding their satisfaction with student services and their experience as online students. Neither had there been a satisfaction assessment given to faculty to learn about their experience as online instructors. To better understand current student satisfaction with support services, a survey was developed by three of the school committees with current online programs (Nursing, Leadership, and Education) to collect this baseline information.

The online student survey was created to gather input from enrolled students in online programs regarding their use, perceptions of, and satisfaction with those services provided by the university and those services specific to the school. This survey consisted of four sections:

- Part 1: respondent demographics and background information

- Part 2: student use and satisfaction with services offered by the school

- Part 3: student use and satisfaction with services offered by the university

- Part 4: suggestions for additional services and improvements to current services

\section{A. COMFORT Model}

\section{RESULTS}

Building upon the findings of Heyman (2010) and Smith (2005) and the spirit of Duquesne's mission statement, our desire was to design a student-centric support service in which the institution and the online student are invested partners in the success of the online student learner [10,11]. The COMFORT 
Building a Foundation for Success through Student Services for Online Learners

model, as we call it, results from this philosophy and is based on trust, responsibility, accountability, and shared goals. The goal is to achieve what LaPadula calls "quality of interaction" [8]. The COMFORT model does not imply the institution compromises in any way its educational standards for the student's happiness or comfort; instead, the relationship is mutually beneficial without either party having to lessen expectations of the other. The model ensures online students will receive prompt, timely, and efficient support services so they can focus on their courses and learning instead of taking precious time from their studies to find services or resolve issues. Through implementation of effective student support services, online students continue to make progress on their degree, are retained, and reach graduation to become alumni. They become "satisfied" students in the terminology of the Sloan-C Five Pillars for Online Program Success [14]. As we describe each part of the COMFORT model within our institutional context with key implementation points for other institutions, refer to figure 1.

\section{Communication Plan in the COMFORT Model}

A well-developed communication plan for students, faculty, and support staff is a critical component of the model because our survey respondents indicated communication of services was often disjointed, confusing, and contradictory. An effective communication plan sets clear expectations for all involved. For example, institutions are responsible for timely delivery of clear, concise, and relevant information necessary to the online student's degree progress, and the students is responsible for reading and acting upon the provided information in a timely manner. Developing a partnership with online students also requires improving relationships with faculty and staff across the university who are involved in supporting online students. In her analysis of post-secondary institutions and student service directors, Dunn (2005) suggests that commonsense practices are often challenged by decentralized institutional structures that on-campus students can navigate more effectively than online students [15]. To construct an effective communication plan at Duquesne, we had to bring together the key constituents necessary to provide student services to online students, which we did through the formation of the task-force committees described earlier. More importantly, we needed to provide a safe and open collaborative space early on for these stakeholders to discuss and learn from each other about communicating necessary information to students. These stakeholders also needed to discuss how each school was delivering information in order to identify and recommend improvements to reduce duplication of materials, streamline messages, and select appropriate information delivery methods.

According to Dunn (2005), communication should not be limited to e-mail, phone, or in-person meetings; an institution should employ any medium available, such as announcements through Blackboard or websites, text messages, social media (Facebook, Twitter), chat (Skype, Collaborate, Oovoo), and even video [15]. Ideally, online students should be able to select their preferred message delivery system. At Duquesne, however, we do not yet have a communication system that enables such an option for students. Therefore, we agreed our first priority was to ensure messages were concise, relevant, and timely and delivered in ways that best meet the needs of online students. The committee defined the following as the keys for a successful communication plan:

- Understand the roles of key support players within the institution and the high-touch points for online students during their academic lifespan.

- Construct a communication plan that key players have ownership of that can be consistently implemented and maintained.

- Understand the needs of the target audience to create clear and concise messages to them.

- Adopt various tools to push communications to online student.

\section{Orientations (plural) in the C.O.M.F.O.R.T Model}

Most of the literature on student services recommends having an orientation to acclimate students to the institution and to their program. Each school at Duquesne offering online education employs some form of orientation for online students. For instance, the School of Nursing requires a one-week, on-campus orientation, while the School of Leadership provides an optional virtual orientation. Whether students attended an on-site or virtual orientation, our survey respondents spoke positively about the overall 
orientation experience. However, they were dissatisfied with the amount of information given and the late release of some information. Our model adopts the term "orientations" to recommend the need for a series of targeted orientations for both online students and the faculty/staff who work with them.

\section{a. Student Orientations}

To reduce attrition, both Crawley (2012) and Harrell (2008) suggested a comprehensive orientation to help online students learn about the institution, be introduced to their program and peers, and to prepare them for course work $[9,16]$. Although Harrell's research is based on community colleges, his findings relate to online students as well [16]. While orientation to Blackboard and other technologies are important, they should neither be the focus nor omitted from orientation [9]. The task-force committees believed that in addition to the technology, online students needed to learn about the structure of the institution and its philosophy; become acquainted with the many student and academic support services available and how to engage with them as online students; the operational structure of the school, its policies, and educational philosophy; the curricular structure of the program and their educational path; and the institutions' expectations and the students' responsibilities. Because Nursing's one-week, oncampus orientation adopts this comprehensive model, Nursing's online students responded most favorably for awareness and use of school support services.

As the number of students entering online programs grows, so does the need to have a frank discussion about the commitment an online program requires of the student to be successful — conversations that need to happen as early as the recruitment and carry through the program. While online programs and degrees have been thought of as less challenging than traditional face-to-face learning, Allen and Seaman (2013) reported that $77 \%$ of their respondents saw online education as equal to or more demanding than face-to-face learning $[1,2]$. Our respondents reported similarly, with $76.3 \%$ of the students indicting student learning in online courses was more academically challenging when compared to traditional faceto-face courses. Allen and Seaman (2013) also reported that online students find online courses as rigorous and demanding as traditional classroom courses [1,2]. Our respondents ranked self-discipline, self-motivation, organization, and time availability as the top requirements for success. To build a successful partnership between online students and the institution, prospective online students should understand up front the expectations and demands of the program so they can plan accordingly so as to not be distracted, overwhelmed, and derailed in the middle of coursework when issues or events occur outside the classroom. By providing students with a comprehensive orientation (either on-campus or virtually), we provide online students with the tools to be successful in their educational experience with us.

\section{b. Faculty/Staff Orientations}

Effective student services is an institutional effort requiring the commitment of all key players within the institution to ensure that online students transition successfully through the stages of their academic lives so that both the students and the institution benefit $[13,17,18]$. Because the characteristics and needs of the online student continue to evolve, it is essential to periodically refresh faculty and staff understanding of who the typical online student is, the needs of the student, the difference from the traditional student, and the student's expectations of the educational experience. By being better informed about the adult online student, faculty and staff can better understand their roles in retention and support services [17]. According to Clinefelter (2012), faculty play a key role in the success of online learners, particularly through the quality, not frequency, of their interactions with students in courses [19]. Not only is an institution's faculty one of the top factors during the selection process for prospective students [2], but as Crawley and Fetzner have noted, "Faculty members are typically the first to know when students are in trouble, and they often are called on to connect these students with the necessary support services" [17, $p$. 7]. Thus, faculty involvement and understanding of their roles in student retention is important to the success of online students, including support service referral. Finally, just as faculty who teach online receive training and development, so should advisors and recruiters who will work with online students. 
The recruiter is the initial face of the institution, while the advisor is a continual presence throughout the student's academic progress.

From our initial development of online student orientations, we have identified the following keys for successful orientations:

- Plan and deliver engaging, student-centric, and learning focused orientations.

- Prioritize sequence of orientations and embed them appropriately into student, faculty, and staff sessions.

- Adopt an appropriate delivery model for the orientation that allows participants to obtain the information they need in the most convenient and flexible manner while creating a feeling connectedness and support by the institution.

- Leverage the "success network" concept existing within the Starfish Retention Systems software Duquesne has adopted to enhance the values of "connectedness" and "partnership" that align with Duquesne's mission and the COMFORT model during the orientation process [20].

- Engage in continuous/periodic evaluation of the orientations for improvement to address the needs of online students, faculty who teach online, and the institutional and school personnel who provide support services to online students.

\section{Maintenance in the COMFORT Model}

While many models and best practices exist for designing effective online education programs in the institution, such as WCET's Best Practices for Electronically Offered Degree and Certificate Programs (2001)[18], the Sloan Consortium's Sloan-C's Quality Framework: The 5 Pillars (2002)[14], and Middle States' Distance Education Programs: Interregional Guidelines for the Evaluation of Distance Education (Online Learning) (rev. 2011) [21], Duquesne's entrepreneurial, early-adopter, and school-specific entrance into online education led schools to focus primarily on curriculum development, technology, content preparation for online delivery, and pedagogical strategies for online teaching with student support services evolving as needs arose. As Hardy and Meyer-Griffith (2012) suggested, it is easy for programs to forget that policies, processes, and procedures also have to be adjusted to align with the needs of online students [22]. Our survey respondents noted that too often, course and institutional tasks seemed tied to faculty preferences, institutional business hours, and staff work schedules than to their needs as working professionals. Mariasingam and Hanna (2006) remind us of the following:

We would be foolish to ignore the fact that ultimately, because of the very nature of elearning, learners (or customers) are able to choose from a multitude of educational offerings regardless of what we or anyone else believes about the quality or legitimacy of such products. We would also be naïve not to recognize that education has become a commodity. It can be bought, sold, and transferred just like any other commodity. And educational providers, whether not-for-profit, public, private, or proprietary, are all ultimately bottom-line driven. If an institution's products do not have market value the institution will not have a market. [23]

Going forward, the task force committees recognized the level of commitment necessary and the importance of this commitment to create, maintain, and sustain support services for online students, and the quality of our interactions with them to retain and graduate them. Some of the keys for successful maintenance of policies, processes, and procedures are as follows:

- Periodically review policies, processes, and procedures to ensure feasibility, clarity, and relevance for online students.

- Centralize and streamline processes for efficiency and effectiveness for both online students and institutional and school stakeholders.

- Leverage existing technology — such as Starfish Retention Solutions, Blackboard, and the Campus portal - to create a one-stop shop or shared resources area to ease navigation issues, reduce time, and eliminate confusion for online students. 
- Create and maintain a feeling of connectedness for online students with the institution even during off-hours, weekends, and holidays so they can complete their work, plan ahead, and problem solve.

\section{Feedback in the COMFORT Model}

Remaining attentive to the needs of online student learners is critical to their success, the program's success, and the institution's success in offering online education [13, 21, 22]. Instituting an assessment cycle of continuous review and improvement is equally important to the success of any program and service $[8,13,22]$. Such assessment helps an institution to determine how well it meets the needs of students and where to make improvements. A comprehensive evaluation plan would incorporate the perspectives of the key stakeholders - students, faculty, and support service staff - and employ a variety of methods, including formal evaluations, such as focus groups or surveys and informal evaluations, such as debriefing meetings with faculty and staff after an event or a discussion board for new ideas $[13,15]$. Additionally, feedback would be collected at various points during the student's academic life regarding satisfaction and use of support services.

The surveys used for our initial assessment are a small piece of a much larger upcoming assessment plan. The current surveys are a starting point for benchmarking this model. They capture current online students' perception and satisfaction with the student services now offered by the university and the schools. As we continue to implement the COMFORT model across current and new online programs, we will focus on what the collected data says about how well the model retains students, helps them continue their progress toward their degree, and as alumni, the level of satisfaction they have for their overall experience as online students at Duquesne University. Early planning for future assessment includes these key factors for successful feedback:

- Create shared governance among stakeholders that includes student and faculty representation to identify the goals, design the assessments, and prioritize the improvements.

- Use various approaches and technologies (Starfish, social media, Blackboard, ticketing systems, etc.) to collect analytics and data on services and interactions.

- Collect and analyze the feedback throughout the year, not just annually.

- Manage changes by implementing them in small but significant ways so as not to be overwhelmed by proposed changes.

- Report assessment findings to current online students and faculty as well as service units and administrators.

\section{Outreach in the COMFORT Model}

Online students are susceptible to feeling isolated because they do not have the same campus experience as traditional students $[16,2]$. Because this sense of isolation is common for online students, it is important for the institution not only to build an online community in which students have the opportunity to interact and socialize with other online students [9], but it is also important for the institution to build relationships and rapport with online students through student services. Oftentimes, as student services practitioners, we are not aware that a student is struggling until the individual hits a breaking point and seeks out assistance. While the faculty may be the first to sense an online student's difficulty in the context of course performance, the faculty may not see it as his or her responsibility to reach out to the student in the same way a student services practitioner might $[16,17]$. By developing a relationship with other online students, these students might be more likely to communicate concerns they have, such as feeling overwhelmed, before these concerns affect their performance in the program [17]. Being proactive with online students demonstrates to them that they are connected to the institution [9]. This outreach begins early in the recruitment phase and should carry through the student's academic life via interactions with support services and an effective communication plan. Each student service representative and faculty is accountable for helping online students be successful. Thus, a collaborative effort is critical to developing a well-planned, well-implemented outreach plan and preventing online students from 
becoming overwhelmed and off track. Research, in combination with our own experiences, led to these keys for successful outreach initiatives:

- The outreach plan should result from a collaborative effort among all institutional stakeholders to limit duplicated communications.

- Outreach should involve an early warning system (such as Starfish Retention Solutions) to identify, connect, and track the outcomes of interventions with at-risk students.

- Outreach should identify potential options for students to consider and make decisions.

\section{Resources in the COMFORT Model}

As LaPadula (2003) and Crawley (2013) explained, student-centric support services are critical to student success $[8,9]$. To construct an effective student service model, Smith (2005) reminds us to keep our target audience in mind so that support services are "available when the learner wants them, rather than when the school is comfortable providing them" [11, p. 29]. Institutions should develop a support environment in which students can use 24/7 self-service options to find answers to their questions; complete common tasks, such as registering for a class, adding or dropping a class, or checking on their progress with financial aid; and access links to handbooks, procedures and forms, academic calendars, and FAQs. Even as $86 \%$ of students surveyed felt that the online student services offered by the university contributed to their success in their program, and $84.7 \%$ of students felt that the online student services contributed to their success in their programs, students gave low satisfaction ratings to other services, such as technology assistance, writing, tutoring and mentoring, and peer and career networking. In the School of Nursing, online students ranked online registration; the Graduate Advisor's Blackboard site containing information on programs, registration, and general program outcomes; and the school's online student portal where polices, handbooks, forms and clinical information can be found as the top three student services offered by the School of Nursing. However, students noted they had to go to three sites to find information; they wanted one place.

Institutional stakeholders must determine what services are critical to online learner and student success before investing in infrastructure, technology, and training. And the institution needs to commit to these support services so resources can be allocated, both financial and human, to building and sustaining the services; otherwise, the institution jeopardizes the partnership they have with online students.

The task force committees identified these key areas for establishing successful learner-focused academic and support resources:

- Commit both financial and human resources from the institution to create, maintain, and grow online support services to students.

- Create student services for online students, not just equivalents services, to foster support and a forge a connection between the school and the online learner.

- Create holistic online support services that focus on the student academically, socially, and individually.

\section{Team-Based Approach in the COMFORT Model}

Retaining students in online education programs requires a cross-unit team that serves as the foundation for the institution's overall focus on online students [15]. Although the team-based approach is the last piece of the COMFORT model, identifying the cross-unit team is the necessary first step to making the other pieces work. The cross-unit team is tasked with implementing the online education vision of the institution and aligning student success strategies with the mission and organizational culture of the institution to build, provide, and sustain streamlined and effective services. The cross-unit team is involved in each of the above parts of the COMFORT model, from the identification and execution of strategies and services to implementing improvements and sharing information. The team includes representatives from each of the high-touch points online students encounter from recruitment to applicant, student, and finally to alumni. The purpose of the cross-unit team is to gather key stakeholders from around the university to create champions within the represented units, reduce potential barriers by addressing them at the planning stage, and limit potential political battles over initiatives by having the 
cross-unit team set the agenda rather than any one unit, department, or service [24]. Commitment to the retention and success of the online student should be a shared goal to ensure the best possible outcome for both students and the institution. The task force committees suggested these key elements for building a team-based approach for student success:

- Align online student support strategies with institutional mission and culture.

- Select key stakeholders invested in holistic and on-going support of student learners.

- View the role of student services as a retention tool for online students.

- Identify best practices from internal institution and external models.

- Implement a well-developed communication plan.

- Involve students and faculty as well as support services staff.

\section{IMPLEMENTATION AND NEXT STEPS}

As explained previously, Duquesne University is in the process of implementing the COMFORT model to address student service needs for online students with the aim of improving retention, enhancing brand reputation, and ensuring success for all students. While the first stages of the COMFORT model are underway, several steps remain both in the short term and long term. Short term goals include the following:

- Enhance current collaboration among recruitment, advisement, faculty, support services, and alumni to ensure online students are being supported holistically across the academic life.

- Implement a unified welcome communication to be sent to all new graduate students upon acceptance to streamline and better coordinate the substance and flow of information new graduate students receive.

- Develop an academic preparedness online orientation for new online students that includes technology preparation, introduction to the library, information on writing resources, overview of institutional structure, and introductions to the support services available.

- Design and construct a New Graduate Student portal able to address rolling admissions for new online graduate students to help them prepare for the start of their programs and complete a checklist of necessary tasks before the start of classes.

- Recommend that orientations for online students be mandatory whether the delivery mode is online or in-person.

- Further the development and use of available technologies, such as Starfish Retention Solutions, across all online programs.

Although the short-term goals continue the work that has begun, the longer-term goals require additional planning, resources and commitment from the university before they are able to be realized. These goals include the following:

- Continual support and commitment is necessary from the deans, academic and business support entities, and the campus community at large in order to construct a sustainable and flexible student support infrastructure for launching new online programs and growing current programs.

- Create professional advisor positions not currently available in schools offering online programs. We attribute part of the School of Nursing and the School of Leadership's success over the years to the role of the professional advisor. Professional advisors often serve as the lifeline between the student and the institution.

- Incorporate additional university services to support online students, such as campus ministry, career services, student organizations, and counseling. While Duquesne has made significant progress over the years in creating online student services, the incorporation of these services would allow the university to further build the critical connectedness between the student and the institution. 
Building a Foundation for Success through Student Services for Online Learners

- Better leverage existing technology across all student services. It is critical that Duquesne use the technology and tools available to better service students and also meet university needs.

- Fully implement the COMFORT model across all online graduate programs. As the university focuses efforts on expanding online programs at the graduate level, the COMFORT model ensures streamlined processes, consistent and accurate information, and available effective and efficient online services and resources are in place to support new online programs and make growth sustainable.

\section{CONCLUSION}

The authors recognize that the COMFORT model may not fit the structure and culture of other institutions or online programs; however, it can at minimum be a starting point for creating a model that will. Successful student support services reflect an institution's ability to identify the very basics of what online students require to move successfully from applicant to alumni. Our COMFORT model is a partnership between the institution and the online student. This partnership lives across the student's academic lifespan; both the student and the institution benefit from the investment in the relationship. Based on trust, responsibility, accountability, and shared goals, this mutually beneficial relationship requires the institution to establish first a commitment to building the necessary team to identify the services, goals, and philosophy to underwrite the online student services. Without such a commitment, the institution jeopardizes the partnership with online students and their success. Next in the process is improving relationships and communication with colleagues across the university involved in supporting online students. From the team's commitment and shared goals (matched by the institution in resources), the design and implementation of the model can begin, followed by continuous improvements.

For online students to commit to the partnership, they must accept and understand up front the expectations and demands of the program, engaging with the provided resources and services when life "happens." By providing consistent, easy to use services and resources targeted toward their individual situations, the institution demonstrates its commitment to the online student's success. The COMFORT model is ambitious and will involve commitment from the institution, allocation of resources, both financial and human, and may require some culture and organizational change to successfully create quality interactions with students. In this case, effective and efficient online student services improve retention and build lasting relationships between the student and institution. Long gone are the days when offering a course or program online gives an institution a competitive advantage in the higher education marketplace. Choice abounds for prospective students and to attract new online students, current online students must have an overall positive experience greatly influenced by the student services they receive while enrolled. We have to do more than be academically rigorous. Our online students must be successful learners, stay focused on their learning, and move toward degree completion. Their success is our success as an institution in the online education market.

\section{ACKNOWLEDGEMENTS}

The authors thank the Duquesne University community, including the administration, deans, the Online Orientation Committee, the Online Student Services Committee, the Academic-Student Affairs Committee, and academic and business support entities for their work in the investigation, evaluation, and beginning steps of the implementation of our COMFORT model. We also thank the online students for their participation in the surveys that have allowed us to take these first steps.

\section{ABOUT THE AUTHORS}

Dr. Ruth Newberry is the current director of Duquesne University's Online Campus, where she provides leadership, advocacy, and support to the university's online initiative by working closely with Academic Affairs, deans, faculty, advisors, enrollment management, and many others across campus. Previously, she was the director of educational technology at Duquesne from 2003 to 2012 and was responsible along 
with her staff for supporting classroom technology, video services, and the Blackboard Learn and Communities systems. During this time, she instituted a sustainability plan for classroom technology, moved the campus from $20 \%$ to $90 \%$ technology-enhanced classrooms, grew Blackboard adoption from $10 \%$ to $85 \%$ for course use, and designed and implemented a required training program for faculty, graduate students, and staff using Blackboard. Drawing upon her teacher preparation background and 18 years of college teaching experience in the traditional and online environments, Ruth has been involved in faculty development, student support, and the effective application of technology to achieve teaching aims and student learning outcomes. She has co-chaired the university's Educational Technology Committee, served on the university's Student Retention and Academic Integrity Committees, and is president of Pittsburgh's Blackboard Users Group (PghBug). In 2005 and 2007, she was conference chair for regional conferences on online learning. Ruth has presented at Sloan, Educause, Mid-Atlantic Educause, Syllabus, Blackboard World, College Composition \& Communication Conference, National Peer Tutoring Conference, and others and is a peer reviewer for Educause Online Review. Her doctorate is in Twentieth-Century American Literature.

Catherine DeLuca joined the Duquesne University School of Nursing in 2004 and has served in various capacities since then, including her current position as the graduate academic advisor. She not only serves as the graduate academic advisor to students, but also as grant manager for some of the school's federal grants in addition to her work at the university level with the Online Campus, Enrollment Management, and Financial Aid departments. She has also been successful in the development and implementation of several new initiatives to enhance the student experience for the online graduate learner. She is currently completing her doctorate in Higher Education Management at the University of Pittsburgh.

\section{REFERENCES}

1. Allen, I., and Seaman, J. Changing Course: Ten Years of Tracking Online Education in the United States. Wellesley, MA: Babson Survey Research Group, 2013.

2. Aslanian, C.B., and Clinefelter, D.L. Online College Students 2013: Comprehensive Data on Demands and Preferences. Louisville, KY: The Learning House, Inc., 2013.

3. Wherry, M., and Windes, D.L. Square Pegs, Round Holes: Distance Students and Campus Priorities in the Academic Community. Continuing Higher Education Review, 74: 110-117 (2010).

4. Braxton, J.M. (Ed.). Reworking the Student Departure Puzzle. Nashville: Vanderbilt University Press, 2000.

5. Boston, W.E., Ice, P., and Gibson, A.M. Comprehensive Assessment of Student Retention in Online Learning Environments. Online Journal of Distance Learning Administration, 4(1) (Spring 2011). http://www.westga.edu/ distance/ojdla/spring141/boston_ice_gibson141.pdf.

6. Slavin, R. Moody's Report Says Grad Enrollment Decline Hits Higher Education Credit. Diverse Issues in Higher Education (October 8, 2012). www.diverseeducation.com/article/48572\#.

7. Duquesne University. Alumni survey results, internal document (2013).

8. LaPadula, M. A Comprehensive Look at Online Student Support Services for Distance Learners. American Journal of Distance Education, 17(2): 119-128 (2003).

9. Crawley, A. Supporting Online Student: A Guide to Planning, Implementing and Evaluating Services. San Francisco: Jossey-Bass, 2012.

10. Heyman, E. Overcoming Student Retention Issues in Higher Education Online Programs. Online Journal of Distance Learning Administration, 13(4) (2010).

11. Smith, B. Online Student Support Services. Community College Journal, 76(2): 26-29 (2005).

12. Duquesne University. Duquesne University's Strategic Plan for 2010-2015. http://www.duq.edu/about/administration/strategic-plan.

13. Pipitone, B., and Poirer, W. Student Services Revitalization/Transformation. College Quarterly, 14(1) (2011). http://www.collegequarterly.ca/2011-vol14-num01-winter/pipitone-poirer.html.

14. The Sloan Consortium. Sloan-C Quality Framework: The Five Pillars, 2002.

http://sloanconsortium.org/5pillars. 
15. Dunn, S. M. A Place of Transition: Directors' Experiences of Providing Counseling and Advising to Distance Students. Journal of Distance Education, 20(2): 40-57 (2005).

16. Harrell, I.L. Increasing the Success of Online Students. Inquiry, 13(1): 36-44 (2008). http://www.vccaedu.org/inquiry/inquiry-spring-2008/1-13-Harrell.html.

17. Crawley, A., and Fetzner, M. Providing Service Innovations to Students Inside and Outside the Online Classroom: Focusing on Student Success. Journal of Asynchronous Learning Networks, 17(1): 7-12 (January 2013).

18. WCET Best Practices to Promote Western Cooperative for Educational Telecommunications (WCET). Best Practices for Electronically Offered Degree and Certificate Programs, 2002. http://wcet.wiche.edu/wcet/docs/cigs/studentauthentication/Accrediting BestPractices.pdf.

19. Clinefelter, D. Best Practices in Online Faculty Development. Learning House White paper, 2012. http://www.learninghouse.com/best-practices-in-online-faculty-development.

20. Starfish Retention Solutions. Starfish Retention Solutions Philosophy, 2013. http://www.starfishsolutions.com/sf/philosophy.php.

21. Middle States Commission on Higher Education. Distance Education Programs: Interregional Guidelines for the Evaluation of Distance Education (Online Learning), 2011, revised. http://www.msche.org/publications/Guidelines-for-the-Evaluation-of-Distance-EducationPrograms.pdf.

22. Hardy, K., and Meyer-Griffith, K. Meeting Accreditation Requirements: Are You Serving Distance Learners? Journal of Asynchronous Learning Networks, 16(5): 7-18 (2012).

23. Mariasingam, M.A., and Hanna, D.E. Benchmarking Quality in Online Degree Programs: Status and Prospects. Online Journal of Distance Learning Administration, 9(3) (Fall 2006).

24. Shea, P. Serving Students Online: Enhancing Their Learning Experience. New Directions for Student Services, 2005(112): 15-24 (2005). 
